\title{
Immuno-gene therapy with interferon- $\beta$ before surgical debulking delays recurrence and improves survival in a murine model of malignant mesothelioma
}

Robert J. Kruklitis, MD, $\mathrm{PhD}^{\mathrm{a}}$

Sunil Singhal, $M D^{\mathrm{b}}$

Peter Delong, MD ${ }^{\mathrm{a}}$

Veena Kapoor, BS ${ }^{\mathrm{a}}$

Daniel H. Sterman, MDa

Larry R. Kaiser, MD

Steven M. Albelda, MDa

From the Pulmonary, Allergy, and Critical Care Division, Department of Medicine ${ }^{\mathrm{a}}$ and Section of Thoracic Surgery, Division of Cardiothoracic Surgery, Department of Surgery, ${ }^{\text {b }}$ University of Pennsylvania School of Medicine, Philadelphia, Pa.

Read at the Eighty-third Annual Meeting of The American Association for Thoracic Surgery, Boston, Mass, May 4-7, 2003.

Received for publication May 2, 2003; revisions received July 30, 2003; accepted for publication Aug 11, 2003

Address for reprints: Dr Steven M. Albelda, Department of Pulmonary Medicine, 857 BRB II/III, 421 Curie Boulevard, Philadelphia, PA 19104 (E-mail: albelda@mail.med. upenn.edu).

J Thorac Cardiovasc Surg 2004;127:123-30 $0022-5223 / \$ 30.00$

Copyright $\odot 2004$ by The American Association for Thoracic Surgery

doi:10.1016/j.jtcvs.2003.08.034
Objectives: Immuno-gene therapy of mesothelioma with an adenovirus encoding interferon- $\beta$ mediated strong antitumor responses in murine models with low but not high tumor burden. Our goals were to determine the mechanisms responsible for this loss of efficacy and to test the hypothesis that the combination of preoperative adenovirus encoding interferon- $\beta$ and surgical resection would be effective in treating bulky tumors.

Methods: Flank tumors of a mouse mesothelioma cell line were treated with adenovirus encoding interferon- $\beta$ or adenoviral vector encoding the bacterial protein $\beta$-galactosidase. Cytotoxic T lymphocytes and tumor infiltration by $\mathrm{T}$ lymphocytes were measured. Tumors were surgically excised 72 hours later and tumor cells were injected in the contralateral flank to create a model of a metastatic focus. Tumor-free survival and distant metastatic disease were assessed.

Results: Immuno-gene therapy effectively treated small tumors $\left(<200 \mathrm{~mm}^{3}\right)$ but did not reduce the size of large $\left(>800 \mathrm{~mm}^{3}\right)$ flank tumors. Although treatment with adenovirus encoding interferon- $\beta$ resulted in the generation of tumor-neutralizing splenocytes in large tumors, the number of $\mathrm{T}$ cells visualized within the tumors was minimal. Tumors treated with adenovirus encoding interferon- $\beta$ (versus adenoviral vector encoding the bacterial protein $\beta$-galactosidase or phosphate-buffered saline solution) prior to debulking increased long-term tumor-free survival and resulted in two- to sixfold smaller foci of implanted tumor cells at 2 weeks postoperatively.

Conclusions: The use of adenovirus encoding interferon- $\beta$ or surgical debulking alone is ineffective in treating large tumors, but combining preoperative adenovirus encoding interferon- $\beta$ and surgical debulking significantly reduces tumor recurrence and improves long-term tumor-free survival. We postulate that adenovirus encoding interferon- $\beta$ amplifies the cytotoxic T-lymphocyte antitumor response, allowing elimination of residual tumor cells.

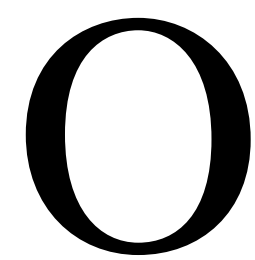

ne of the most intriguing but as yet unfulfilled approaches to antitumor treatment is immunotherapy. When successful, immunotherapy stimulates endogenous antitumor immunity to the point of eradicating established tumors. This treatment approach holds promise for tumors such as malignant mesothelioma whose prognosis is otherwise dismal. Various interferons, interleukins, and cytokines may stimulate antitumor immunity. Cytokines such as interleukin-2 (IL-2), GM-CSF, IL-12, interferon- $\alpha$ (IFN- $\alpha$ ), and IFN- $\beta$ have been tried. ${ }^{1-5}$ How- 
ever, systemic administration of cytokines has resulted in considerable toxicity in both human and murine models. ${ }^{4,6,7}$ The strategy of using viral gene transfer to directly introduce various cytokines into tumor cells has thus been proposed. ${ }^{5,8}$ This provides an increased local concentration of cytokines while minimizing the systemic toxicities.

We have previously demonstrated that intraperitoneal administration of an adenoviral vector encoding the cytokine IFN- $\beta$ (Ad.IFN- $\beta$ ) could cure early-stage malignant mesothelioma in murine models. ${ }^{9,10}$ However, like most immunotherapeutic strategies, efficacy was much lower in animals with large tumor burdens. ${ }^{11-13}$

The objectives of this study were to determine why immunotherapy with Ad.IFN- $\beta$ was ineffective against a larger tumor burden and to assess the efficacy of combining preoperative Ad.IFN- $\beta$ with surgical debulking. The role of surgical debulking or cytoreductive surgery alone has been controversial. ${ }^{14-18}$ Despite small increases in survival for patients with advanced-stage disease, the majority of patients succumb to their disease, reinforcing the inadequacy of cytoreduction. Treatment of malignant mesothelioma is no exception. Surgical debulking, either alone or in combination with conventional chemo- or radiotherapy, has resulted in only small survival benefit. ${ }^{19-21}$

Debulking surgery ultimately fails due to the small numbers of tumor cells that remain after resection. It is thus logical to postulate that immuno-gene therapy, which can effectively eradicate a small tumor burden, could be highly effective when combined with cytoreductive surgery. ${ }^{11,22,23}$ We therefore tested the combination of Ad.IFN- $\beta$ immunogene therapy before surgical debulking to treat large mesothelioma tumors in a syngeneic mouse model.

\section{Materials and Methods}

\section{Cell Lines and Adenoviral Vectors}

The mouse mesothelioma cell line AB12 and the Ad.IFN- $\beta$ have been previously described. ${ }^{9}$ AB 12 cells are an aggressive mouse mesothelioma cell line generated by intraperitoneal injection of asbestos. L1C2 cells are a bronchioalveolar cell line obtained from American Type Culture Collection (Manassas, Va). A control adenoviral vector encoding the bacterial protein $\beta$-galactosidase (Ad.LacZ) was obtained from the vector core at the University of Pennsylvania Medical Center.

\section{Experimental Animals}

All experiments used immunocompetent female BALB/c mice (6-8 weeks old; weight, $\sim 20-25 \mathrm{~g}$ ) that were obtained from Taconic Laboratory (Germantown, NY). The University of Pennsylvania and the Animal Use Committees of the Wistar Institute approved all protocols in compliance with the Guide for the Care and Use of Laboratory Animals.

\section{AB12 Flank Tumor Model}

An AB12 flank tumor model was established to examine the treatment efficacy of locally administered Ad.IFN- $\beta$. AB12 cells $\left(5 \times 10^{5}\right.$ in $100 \mu \mathrm{L}$ of serum-free Dulbecco's modified Eagle's medium [DMEM]) were injected subcutaneously into the flanks of $\mathrm{BALB} / \mathrm{c}$ mice. Mice received a single intratumoral injection of Ad.IFN- $\beta$ at a dose of $10^{9}$ plaque forming units (pfu) at the designated time or tumor volume. This dose is close to the maximally tolerated dose and was chosen based on previous titration experiments. ${ }^{9}$ Tumor volume was calculated by the following formula, where length is the longest diameter and width is the diameter along the perpendicular axis: Tumor volume $\left(\mathrm{mm}^{3}\right)=(\pi / 6) \cdot($ Length $) \cdot(\text { Width })^{2}$.

Control mice were treated in an analogous manner with injection of either $10^{9}$ pfu Ad.LacZ virus or $100 \mu \mathrm{L}$ of phosphatebuffered saline solution (PBS) as indicated. Animals were killed when they met predetermined criteria established for minimizing pain and suffering.

\section{Winn Assay for the Detection of Tumor Neutralizing Cells}

Splenocytes were isolated from spleens (2 mice/group) that were harvested 8 to 10 days after intratumoral treatment with Ad.IFN- $\beta$ or control Ad.LacZ virus. The isolated splenocytes were purified using lymphocyte isolation solution (Ficoll-Paque Plus; Amersham Biosciences, Piscataway, NJ) and then suspended in serumfree DMEM. In some experiments, the $\mathrm{CD}^{+} \mathrm{T}$ cells were separated from the total splenocyte pool using MACS isolation system (CD8a [Ly-2] mouse MicroBeads; Miltenyi Biotec, Auburn, Calif). The isolated cells consisted of greater than $90 \% \mathrm{CD}^{+} \mathrm{T}$ cells as determined by fluorescence-activated cell sorter analysis. The $\mathrm{CD}^{-}$cell pool comprised those cells that did not adhere to the column.

Fresh AB12 cells (or in some cases, L1C2 cells) were then mixed with the splenocytes (Winn $\mathrm{Assay}^{24}$ ) in a ratio of 10 splenocytes to $1 \mathrm{AB} 12$ tumor cell. The resulting mixture $(100 \mu \mathrm{L}$; $5 \times 10^{6}$ splenocytes and $5 \times 10^{5} \mathrm{AB} 12$ cells) was injected subcutaneously into the flanks of 5 naïve BALB/c mice. A control group of 5 mice with $\mathrm{AB} 12$ cells alone $\left(5 \times 10^{5}\right.$ in $\left.100 \mu \mathrm{L}\right)$ were injected in an analogous fashion. When $\mathrm{CD} 8^{+} \mathrm{T}$ cells were used, they were mixed with $\mathrm{AB} 12$ cells or L1C2 cells in a ratio of 3 $\mathrm{CD}^{+}$cells to $1 \mathrm{AB} 12$ cell as $\mathrm{CD} 8^{+} \mathrm{T}$ cells make up about $30 \%$ of the total splenocytes. In these experiments, the injected mixture thus contained $1.5 \times 10^{6} \mathrm{CD}^{+} \mathrm{T}$ cells and $5 \times 10^{5} \mathrm{AB} 12$ cells. Tumor size was assessed over the next 14 days.

\section{Immunohistochemistry}

Dissected flank tumors were snap-frozen in Tissue-Tek ornithine carbamoyltransferase (Sakura Finetek, Torrance, Calif), sectioned at $4 \mu \mathrm{m}$ onto gelatin-coated slides, and fixed in cold acetone. We performed immunoperoxidase staining by using the avidin-biotinperoxidase Vectastain Elite ABC kit (Vector Laboratories, Burlingame, Calif). Primary antibodies were mAbs anti-CD4 (GK 1.5) and anti-CD8 (Ly-2) (Southern Biotechnology, Birmingham, Ala).

\section{Debulking Surgery}

Mice with flank tumors greater than $800 \mathrm{~mm}^{3}$ were anesthetized and shaved. An incision 1 to $2 \mathrm{~cm}$ was made immediately adjacent to the tumor. The mass was then completely excised using standard blunt dissection. Occasionally it was necessary to remove skin that was adherent to the tumor. If the tumor was found to be extending through the abdominal wall, the mouse was excluded as debulking 


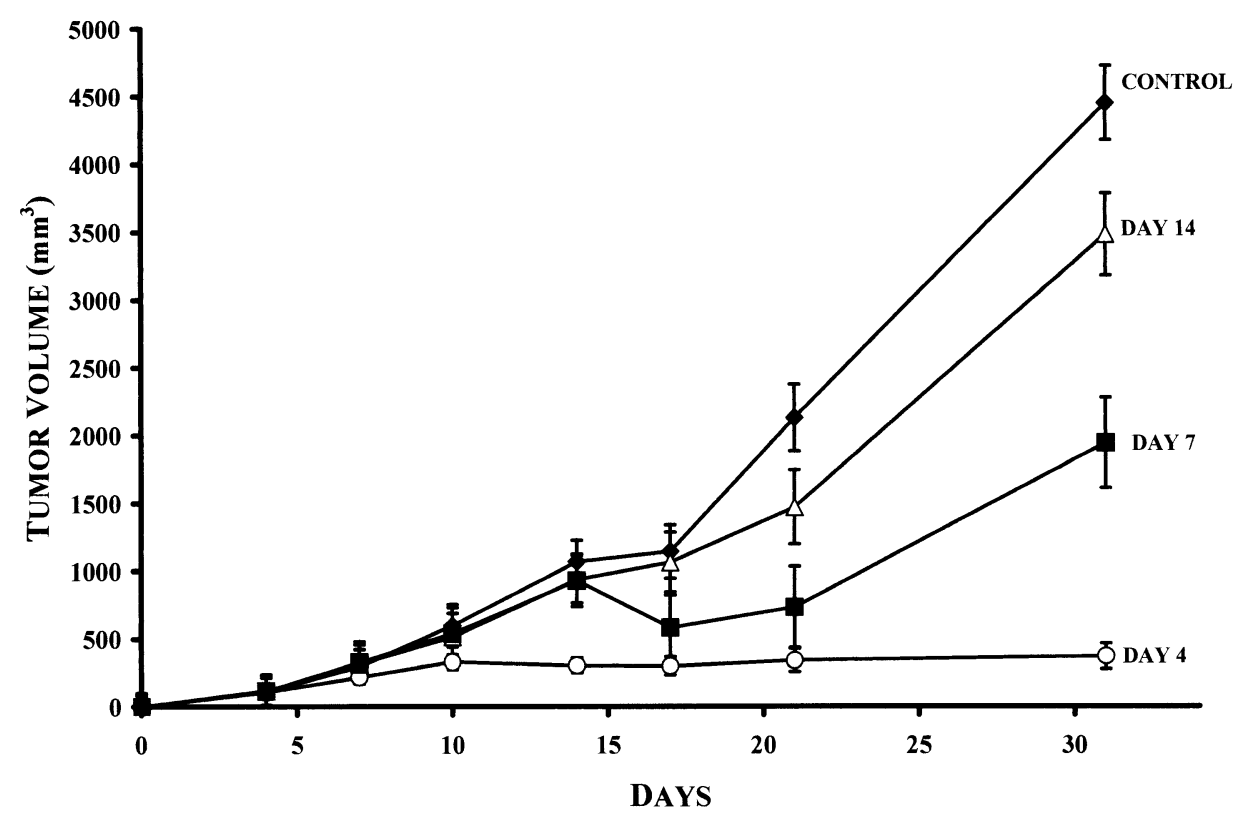

was not possible (less than $5 \%$ of mice). Skin closure was performed using sterile 3-0 sutures. Preoperative treatment was unknown to the investigator performing surgery and making tumor measurements.

\section{Tumor Rechallenge in Mice Treated with Neoadjuvant Ad.IFN- $\beta$}

At the time of tumor debulking, animals from the above experiments were rechallenged in the contralateral flank with subcutaneous injections of $5 \times 10^{5}$ cells of $\mathrm{AB} 12$ cells in $100 \mu \mathrm{L}$ of serum-free DMEM.

\section{Statistical Analysis}

Tumor volumes are reported throughout the text as mean tumor volume. We analyzed differences by Student $t$ test ( 2 groups) or 1-way analysis of variance (ANOVA) for multiple comparisons with appropriate post hoc testing. Fisher exact test was used for categorical data. Survival was calculated from the date of surgery. Results are expressed as mean \pm standard error of the mean.

\section{Results}

\section{Immuno-Gene Therapy Loses Efficacy as Tumor} Burden Increases

AB12 mesothelioma tumors were established in the flanks of BALB/c mice. After 4, 7, or 14 days, mice were injected intratumorally with Ad.IFN- $\beta$. The average tumor volumes at the time of injection were $111 \pm 63 \mathrm{~mm}^{3}, 293 \pm 75 \mathrm{~mm}^{3}$, and $929 \pm 89 \mathrm{~mm}^{3}$ at days 4,7 , and 14, respectively.

As shown in Figure 1, the efficacy of Ad.IFN- $\beta$ depended on the tumor size at time of treatment. Treatment of tumors at day 4 and day 7 led to statistically significant decreases in tumor size versus control at day $31(P<.001)$; administration of Ad.IFN- $\beta$ to small tumors $\left(<200 \mathrm{~mm}^{3}\right)$ typically resulted in complete response. Greater than $80 \%$ of the mice remained disease-free for more than 45 days following treatment. In contrast, administration of Ad.IFN- $\beta$ to larger tumors $\left(200-800 \mathrm{~mm}^{3}\right)$ was less effective. When tumor volume exceeded $800 \mathrm{~mm}^{3}$, Ad.IFN- $\beta$ administration had no statistically significant effect on tumor growth. These findings demonstrate that the benefit of immuno-gene therapy diminishes as tumor burden increases.

\section{Ad.IFN- $\beta$ Therapy Stimulates a Cellular Antitumor Response Independent of Tumor Size}

Animals with small $\left(75-200 \mathrm{~mm}^{3}\right)$ and large AB12 flank tumors (800-1200 $\mathrm{mm}^{3}$ ) had their splenocytes harvested, mixed with viable tumor cells, and then injected into naïve mice. As shown in Figure 2, A, splenocytes from animals bearing small tumors significantly $(P<.05)$ inhibited the growth of new tumors. In contrast, splenocytes from animals bearing large tumors had no significant effect on tumor growth $\left(382 \pm 37 \mathrm{~mm}^{3}\right.$ in small tumors vs $814 \pm 43 \mathrm{~mm}^{3}$ in large tumors, $P<.05$, at 12 days).

The effect of Ad.IFN- $\beta$ treatment on the generation of tumor-killing splenocytes in animals with large tumors was then assessed. As shown in Figure 2, B, the splenocytes from the Ad.IFN- $\beta$-treated-mice inhibited tumor growth to a greater degree than the splenocytes from the Ad.LacZ- 

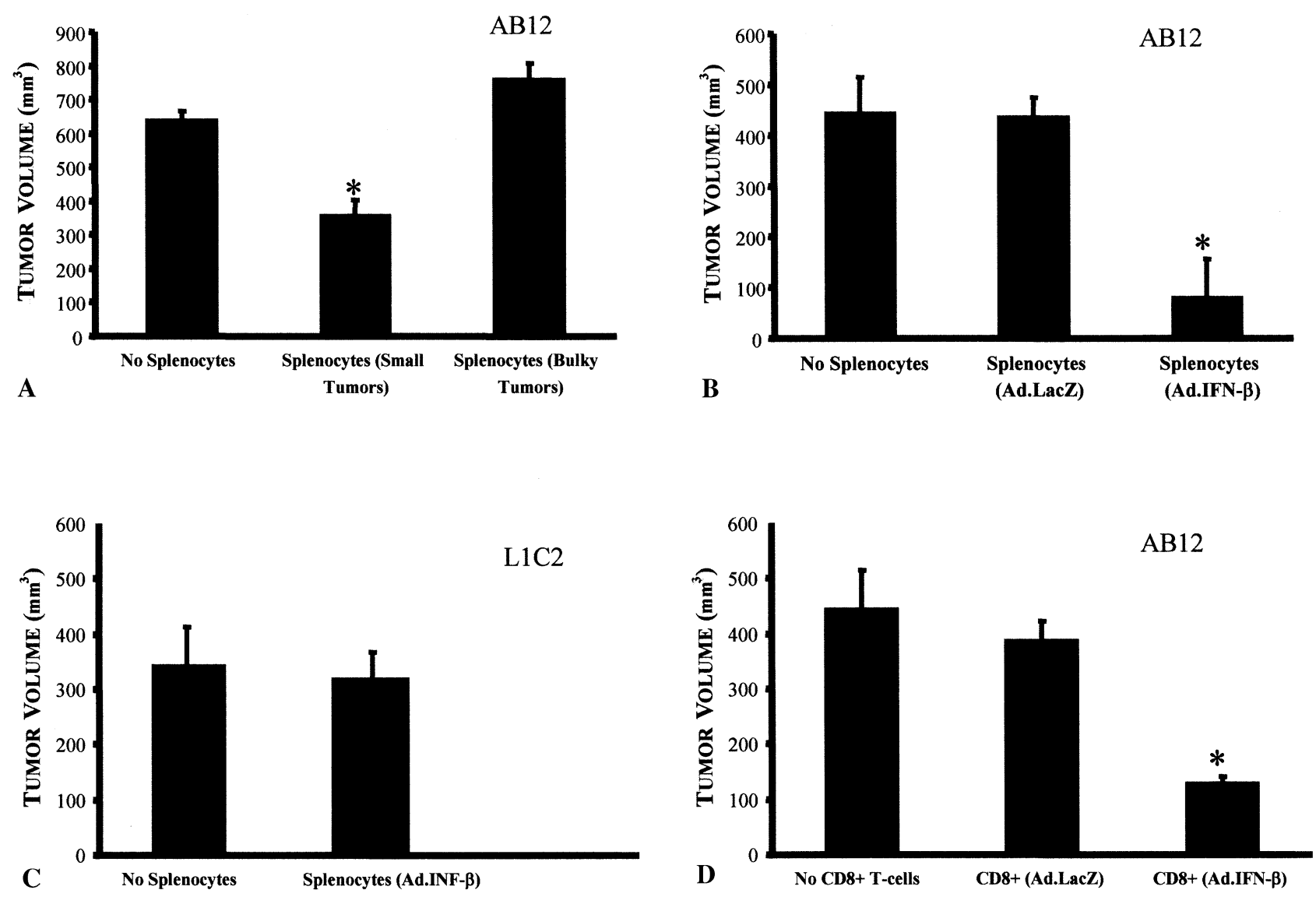

Figure 2. Assessment for tumor-neutralizing cells using the Winn Assay. A, Splenocytes were isolated from mice bearing either small $\left(75-200 \mathrm{~mm}^{3}\right)$ or large $\left(800-1100 \mathrm{~mm}^{3}\right)$ AB12 flank tumors and mixed with fresh AB12 tumor cells. Each mixture was injected into naïve mice and tumor volumes were measured on day 7 . $B$, Splenocytes from large $\left(800-1100 \mathrm{~mm}^{3}\right)$ flank tumors that had been treated with either Ad.IFN- $\beta$ or Ad.LacZ were isolated and mixed with AB12 tumor cells or (C) with L1C2 lung cancer cells. Each mixture was injected into naïve mice and tumor volume measured on day 7. D, Similar studies in animals with large flank tumors treated with either Ad.IFN- $\beta$ or Ad.LacZ were performed using purified $\mathrm{CD8}^{+} \mathrm{T}$ cells mixed with $\mathrm{AB12}$ tumor cells. ${ }^{*} \boldsymbol{P}<.01$ compared with both other groups.

treated mice $\left(81 \pm 75 \mathrm{~mm}^{3}\right.$ vs $437 \pm 37 \mathrm{~mm}^{3}, P<.05$, at 7 days). This tumor-neutralizing capability was specific for AB12 tumor cells; splenocytes from Ad.IFN- $\beta$-treated mice did not inhibit the growth of L1C2 lung adenocarcinoma tumors (Figure 2, C).

To determine which cells were responsible for this antitumor effect, we isolated $\mathrm{CD} 8^{+} \mathrm{T}$ cells. Similar to our data with total splenocytes, the rate of tumor development in mice injected with the mixture of tumor cells and $\mathrm{CD} 8^{+} \mathrm{T}$ lymphocytes isolated from Ad.IFN- $\beta$-treated mice was significantly less than in those treated with Ad.LacZ (120 \pm 18 $\mathrm{mm}^{3}$ vs $388 \pm 35 \mathrm{~mm}^{3}, P<.01$, at 7 days; Figure $\left.2, D\right)$. Thus, cytotoxic $\mathrm{T}$ lymphocytes (CTLs) are generated after injection of Ad.IFN- $\beta$ into mice with large tumor burdens; however, as shown in Figure 1, these $\mathrm{CD}^{+}$cells are not able to effectively alter tumor progression in animals with bulkier tumors.
Inadequate CTL Tumor Infiltration Contributes to Failure of Immuno-Gene Therapy in Large Tumors We examined both small and large flank tumors, treated either with Ad.IFN- $\beta$ or control, using immunohistochemistry. Eight days following viral injection, tumor-bearing mice were killed and the flank tumors harvested and stained.

As shown in the top panel in Figure 3, Ad.LacZ-injected (control) tumors had very few $\mathrm{CD}^{+}$or $\mathrm{CD}^{+} \mathrm{T}$ cells within the core of small tumor nodules. However, intratumoral injection of Ad.IFN- $\beta$ into small tumors resulted in a clear increase in the number of infiltrating $\mathrm{CD} 4^{+}$and $\mathrm{CD} 8^{+}$ $\mathrm{T}$ cells (Figure 3, upper panel). In contrast, in animals bearing large tumors, Ad.IFN- $\beta$ treatment did not lead to increased numbers of infiltrating $\mathrm{CD} 4^{+}$or $\mathrm{CD}^{+} \mathrm{T}$ cells (Figure 3, bottom panel). These data support the hypothesis that the lack of efficacy of Ad.IFN- $\beta$ therapy in bulkier 


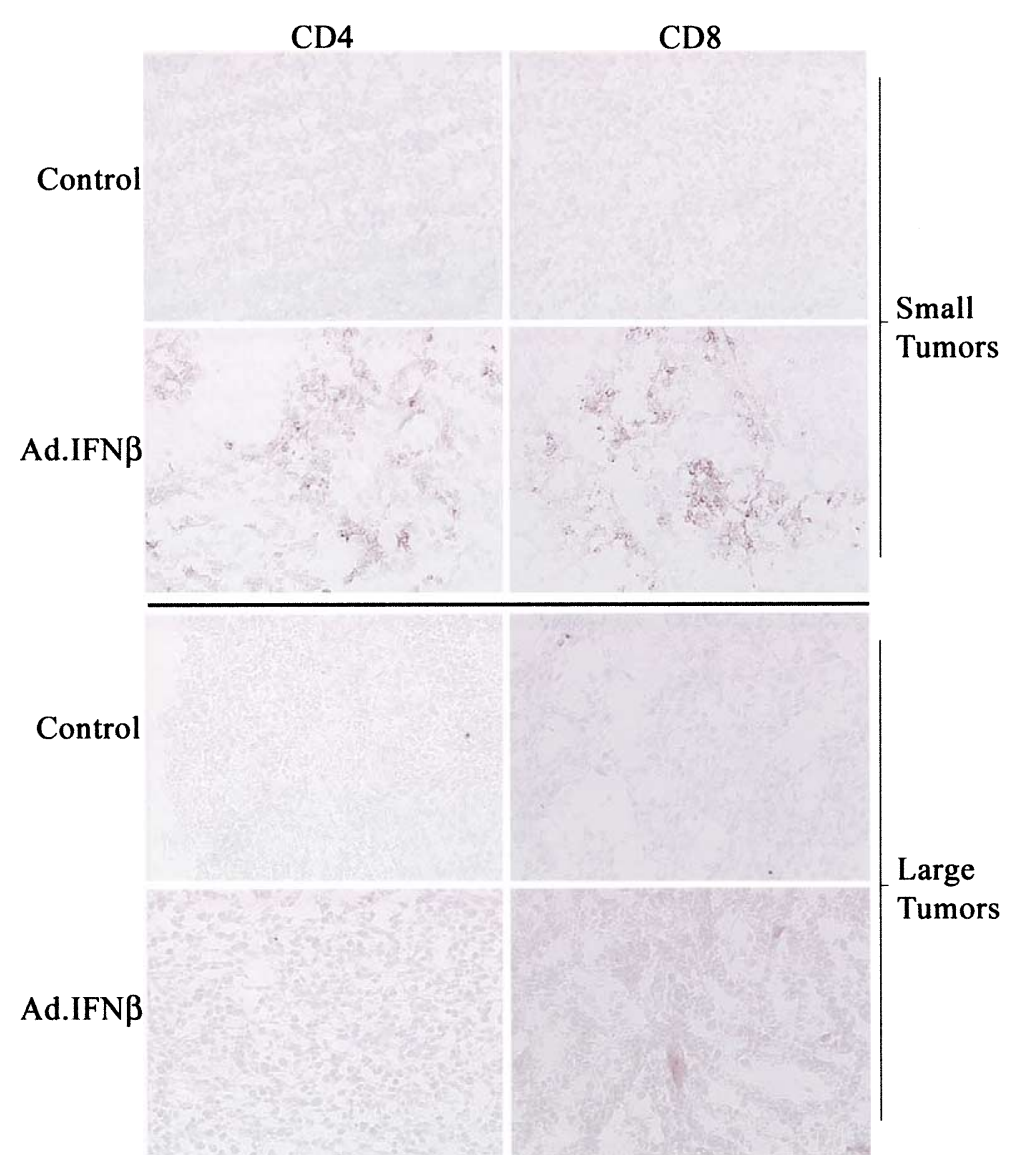

Figure 3. $\mathrm{CD}^{+}$and $\mathrm{CD8}^{+} \mathrm{T}$ lymphocytes infiltrate small but not large tumors following Ad.IFN- $\beta$ treatment. Mice bearing small $\left(75-200 \mathrm{~mm}^{3}\right)$ (upper panel) and large $\left(800-1100 \mathrm{~mm}^{3}\right.$ ) (lower panel) flank tumors were treated with Ad.LacZ and Ad.IFN- $\beta$. Flank tumors were harvested, sectioned, and stained for CD4 ${ }^{+}$and CD8 $^{+}$T cells 8 days following treatment.

tumors is due, at least in part, to the inability of $\mathrm{CD}^{+}$and $\mathrm{CD}^{+} \mathrm{T}$ cells to infiltrate into or persist in bulky tumors.

\section{Addition of Preoperative Viral Gene Therapy to Surgical Debulking Provides More Effective Therapy of Large Tumors}

Because Ad.IFN- $\beta$ injection of large tumors induced splenocytes and $\mathrm{CD} 8^{+} \mathrm{T}$ cells with antitumor activity, we reasoned that removal of the large tumor mass might allow these immunocytes to effectively kill small amounts of residual tumor. Large flank tumors $\left(>800 \mathrm{~mm}^{3}\right)$ were thus treated with either Ad.IFN- $\beta(n=5)$ or Ad.LacZ $(n=5)$. Three days later, the tumors were excised. This experimental design allowed direct injection of a large number of tumor cells that would not be possible with perioperative or postoperative injection. As shown in Figure 4, A (results from 1 experiment), pretreatment of the tumors with Ad.IFN- $\beta$ led to a significant $(P<.01)$ increase in the number of animals that remained tumor-free. In 4 replicate experiments, treatment with Ad.IFN- $\beta(\mathrm{n}=34)$ versus
Ad.LacZ $(\mathrm{n}=10)$ or PBS $(\mathrm{n}=18)$ prior to surgical debulking resulted in a delay of local tumor recurrence (mean recurrence time: 19 days vs 6 days, $P<.01$ ) and an increase in 25 -day disease-free survival (58\% vs $11 \%, P<$ .01 ; Table 1).

To further test the benefits of surgical debulking, viable AB12 tumor cells were injected into the contralateral flank at the time of operation to model a focus of unresected metastatic disease. Although tumors ultimately developed, the tumors were significantly smaller on both day $17(P<$ $.05)$ and day $25(P<.05)$ with neoadjuvant Ad.IFN- $\beta$ compared with debulking alone (Figure $4, B$ ).

\section{Discussion}

Malignant mesothelioma is an aggressive tumor of serosal surfaces (pleura, pericardium, peritoneum) that is highly associated with asbestos exposure. Despite aggressive therapy including surgical resection, chemotherapy, and radiation therapy, the median life expectancy is still 12 to 16 

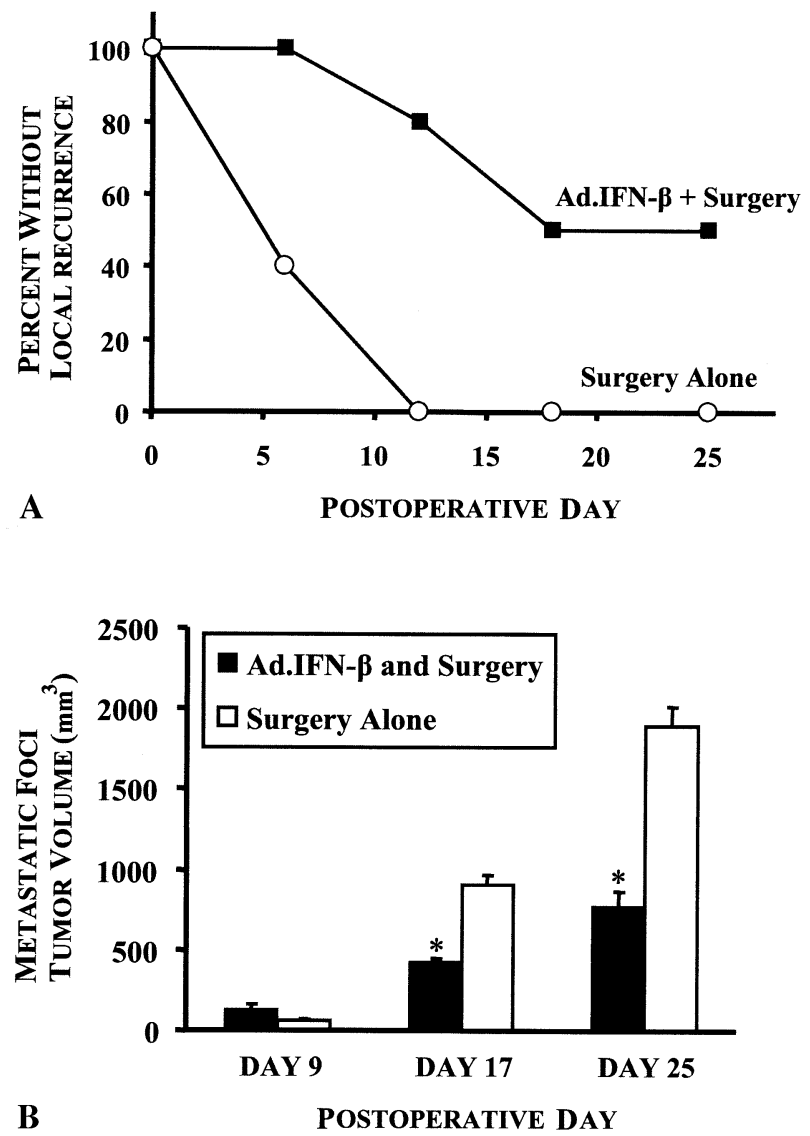

Figure 4. Neoadjuvant Ad.IFN- $\beta$ delays tumor recurrence and prolongs tumor free survival. $A$, Large AB12 flank tumors (800-1000 $\mathrm{mm}^{3}$ ) were treated with Ad.IFN- $\beta$ (squares) or PBS (circles). Three days following treatment the tumors were surgically debulked. Mice were followed for local recurrence. The percent of mice tumor-free versus time after surgery is plotted. B, Growth of metastatic foci was measured. ${ }^{*} \boldsymbol{P}<.01$ compared with surgery alone. Note: Each experimental group contained 5 mice; all experiments were repeated in triplicate with similar results.

months from time of diagnosis. ${ }^{19}$ Therefore, novel treatment approaches, such as immunotherapy, are desperately needed for this devastating disease.

We have previously shown that Ad.IFN- $\beta$ was highly effective in treating small but established tumors in a mouse intraperitoneal mesothelioma model. ${ }^{9,10}$ Unfortunately, in our animal studies, the efficacy of Ad.IFN- $\beta$ immunotherapy was greatly diminished with increasing tumor burden. There are a number of reasons to account for the lack of efficacy of immunotherapy against large tumor burdens. We have demonstrated that although cytotoxic $\mathrm{T}$ lymphocytes are generated after treatment of large tumors with Ad.IFN- $\beta$, they fail to effectively traffic into or persist in established large tumors. Continued tumor growth may simply be a reflection of ineffective CTL trafficking. Alterna-
TABLE 1. Neoadjuvant Ad.IFN- $\beta$ therapy decreases recurrence rate following debulking surgery

\begin{tabular}{cc}
\hline $\begin{array}{l}\text { Neoadjuvant Ad.IFN- } \boldsymbol{\beta} \\
\text { (cured:treated) }\end{array}$ & $\begin{array}{c}\text { Ad.LacZ/PBS control } \\
\text { (cured:treated) }\end{array}$ \\
\hline $4: 4$ & $0: 3$ \\
$3: 10$ & $0: 10$ \\
$4: 5$ & $1: 5$ \\
$5: 10$ & $0: 5$ \\
$4: 5$ & $2: 5$ \\
Total cured: $20: 34(58 \%)^{*}$ & Total cured: $3: 28(11 \%)^{*}$
\end{tabular}

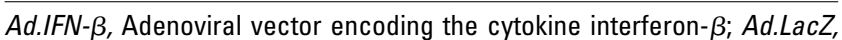
adenoviral vector encoding the bacterial protein $\beta$-galactosidase; $P B S$, phosphate-buffered saline solution.

A series of individual experiments were performed in which mice with large flank tumors $\left(800-1500 \mathrm{~mm}^{3}\right)$ were treated with neoadjuvant Ad.IFN- $\beta$ or control (Ad.LacZ or PBS). Subsequently tumors were surgically excised. The data denotes the ratio of "cured" animals (defined as tumor-free for 25 days following surgical debulking) to the total number of animals treated. The percentage of animals "cured" after neoadjuvant Ad.IFN- $\beta$ was significantly higher ( $P<.001$; chi-square) than control animals.

*58\% versus $11 \%, P<.001$, chi-square analysis.

tively, other mechanisms, which have yet to be defined, might contribute to the diminished antitumor efficacy. For instance, the generated CTLs may simply be outnumbered by the vast quantities of viable tumor cells in bulky tumors, thus making tumor destruction impossible. Another factor may be the altered vascularity within a large tumor mass. ${ }^{24}$ It is also probable that an immunosuppressive environment exists within bulky tumors. ${ }^{11,22}$ It has been demonstrated that both tumor cells and infiltrating cells (immature myeloid cells, T-regulatory cells, suppressive macrophages) elaborate immunosuppressive factors such as prostaglandin $\mathrm{E}_{2}$, tumor growth factor (TGF)- $\beta$, IL-10, and vascular endothelial growth factor in bulky tumors. ${ }^{12,25}$ These immunosuppressive factors can inhibit CTL trafficking and induce apoptosis of antitumor cells that enter the tumor. ${ }^{24}$

\section{Strategies to Overcome the Immunosuppression of Large Tumors}

Various strategies have been used to decrease the immunosuppressive environment in large tumors. We have preliminary data that cyclooxygenase- 2 inhibitors are effective by decreasing the formation of prostaglandin $\mathrm{E}_{2}$ and IL-10. Other approaches such as neutralization of TGF- $\beta^{26}$ using either antisense or monoclonal antibodies or removal of T-regulatory cells by depletion with anti-CD25 antibodies ${ }^{27}$ have also shown promising results.

We opted to test a different approach. We reasoned that debulking surgery would both decrease the number of viable tumor cells (improving the antitumor $\mathrm{CD}^{+}$to tumor cell ratio) and greatly diminish the production of immunosuppressive cytokines. This would allow the CTLs generated by Ad.IFN- $\beta$ therapy to more effectively kill any 
remaining tumor cells. Furthermore, there are data to support the idea that debulking surgery might augment antitumor immune responses. Specifically, tumor resection might unmask a population of primed $\mathrm{T}$ cells able to mediate protective immunity. ${ }^{13}$ Additionally, resection has been shown to enhance the immune response by reducing negative immune modulators and suppressors of local immune response, ${ }^{28}$ restoring colony growth inhibition ${ }^{29}$ and preventing immunological overburdening. ${ }^{30}$

Surgical debulking alone in our animal model was largely ineffective. Likewise, immuno-gene therapy alone was ineffective with increased tumor burden. However, the combination of immuno-gene therapy followed by surgical debulking was much more effective at treating mice with large tumors. These results are consistent with previous work showing that neoadjuvant therapy with IL-12-loaded polylactic acid microspheres reduced local recurrence and distant metastases. ${ }^{22,23}$

We suggest that intratumoral injection of Ad.IFN- $\beta$ triggers an antitumor immune response that is mediated via $\mathrm{CD} 8{ }^{+}$CTLs. Although ineffective against large tumors, this immune response is capable of controlling the residual disease that is undoubtedly left behind following debulking surgery. We postulate that by giving Ad.IFN- $\beta$ preoperatively, the immune system is primed to eliminate residual tumor cells before these cells have a chance to repopulate.

\section{Potential Limitations}

Admittedly, there are some limitations to this animal model. Although mesothelioma is predominately an intrapleural and intraperitoneal disease, we have studied flank tumors in mice. This model allowed us to readily monitor tumor burden, perform complete tumor resections, and assess for recurrent disease. It is not yet known for certain how these findings will translate to an intracavitary tumor model.

In these studies, we utilized an adenovirus expressing murine interferon- $\beta$ in murine mesothelioma cell lines because immune responses are the key to our therapeutic effects. We were unable to use human mesothelioma cell lines as they can only be grown in immunodeficient animals. Some biological differences between the response of tumor cells to murine and human interferons may exist. For example, there is some data to suggest that there may be a greater direct cytotoxic effect with human IFN- $\beta$, perhaps suggesting that it could be even more efficacious than murine IFN- $\beta$.

The optimal timing of immunotherapy in relation to surgical debulking also remains to be determined. In our experiments, we administered immunotherapy prior to surgical resection, allowing sufficient time to generate an antitumor immune response. Alternative approaches, such as administration of immunotherapy into the tumor bed at the time of resection or following resection, were difficult to assess in our model but may be possible in clinical scenarios.

With these caveats in mind, we suggest that the strategy of administering immunotherapy followed by surgical resection may provide a technique to optimize immuno-gene therapy in clinical practice.

\section{References}

1. Monnet I, Breau JL, Moro D, et al. Intrapleural infusion of activated macrophages and gamma-interferon in malignant pleural mesothelioma: A phase II study. Chest. 2002;121:1921-7.

2. Boutin C, Viallat JR, Van Zandwijk N, et al. Activity of intrapleural recombinant gamma-interferon in malignant mesothelioma. Cancer. 1991;67:2033-7.

3. Bielefeldt-Ohmann H, Fitzpatrick DR, Marzo AL, Jarnicki AG, Musk AW, Robinson BW. Potential for interferon-alpha-based therapy in mesothelioma: Aassessment in a murine model. J Interferon Cytokine Res. 1995;15:213-23.

4. Astoul P, Viallat JR, Laurent JC, Brandely M, Boutin C. Intrapleural recombinant IL-2 in passive immunotherapy for malignant pleural effusion. Chest. 1993;103:209-13.

5. Mukherjee S, Haenel T, Himbeck R, et al. Replication-restricted vaccinia as a cytokine gene therapy vector in cancer: Persistent transgene expression despite antibody generation. Cancer Gene Ther. 2000; 7:663-70.

6. Pass HW, Temeck BK, Kranda K, Steinberg SM, Pass HI. A phase II trial investigating primary immunochemotherapy for malignant pleural mesothelioma and the feasibility of adjuvant immunochemotherapy after maximal cytoreduction. Ann Surg Oncol. 1995;2:214-20.

7. Von Hoff DD, Metch B, Lucas JG, Balcerzak SP, Grunberg SM, Rivkin SE. Phase II evaluation of recombinant interferon-beta (IFNbeta ser) in patients with diffuse mesothelioma: A Southwest Oncology Group study. J Interferon Res. 1990;10:531-4.

8. Smythe WR, Kaiser LR, Hwang HC, et al. Successful adenovirusmediated gene transfer in an in vivo model of human malignant mesothelioma. Ann Thorac Surg. 1994;57:1395-401.

9. Odaka M, Sterman DH, Wiewrodt R, et al. Eradication of intraperitoneal and distant tumor by adenovirus-mediated interferon-beta gene therapy is attributable to induction of systemic immunity. Cancer Res. 2001;61:6201-12.

10. Odaka M, Wiewrodt R, DeLong P, et al. Analysis of the immunologic response generated by Ad.IFN-beta during successful intraperitoneal tumor gene therapy. Mol Ther. 2002;6:210-8.

11. Hill HC, Conway TF Jr, Sabel MS, et al. Cancer immunotherapy with interleukin 12 and granulocyte-macrophage colony-stimulating factorencapsulated microspheres: Conduction of innate and adaptive antitumor immunity and cure of disseminated disease. Cancer Res. 2002; 62:7254-63.

12. Salih HR, Nussler V. Commentary: Immune escape versus tumor tolerance: how do tumors evade immune surveillance? Eur J Med Res. 2001;6:323-32.

13. Salvadori S, Martinelli G, Zier K. Resection of solid tumors reverses T cell defects and restores protective immunity. J Immunol. 2000;164: 2214-20.

14. Lejeune FJ, Lienard D, Sales F, Badr-el-Din H. Surgical management of distant melanoma metastases. Semin Surg Oncol. 1992;8:381-91.

15. Karrer K. Rationale for surgery as the first step in the multimodality treatment of small cell lung cancer (SCLC). J Chemother. 1989;1:14750 .

16. Gulec SA, Mountcastle TS, Frey D, et al. Cytoreductive surgery in patients with advanced-stage carcinoid tumors. Am Surg. 2002;68: 667-71 (discussion 71-2).

17. Le T, Krepart GV, Lotocki RJ, Heywood MS. Does debulking surgery improve survival in biologically aggressive ovarian carcinoma? $G y-$ necol Oncol. 1997;67:208-14.

18. van der Burg ME. Advanced ovarian cancer. Current Treatment Options in Oncology. 2001;2:109-18.

19. Pass HI, Kranda K, Temeck BK, Feuerstein I, Steinberg SM. Surgi- 
cally debulked malignant pleural mesothelioma: Results and prognostic factors. Ann Surg Oncol. 1997;4:215-22.

20. Martin-Ucar AE, Edwards JG, Rengajaran A, Muller S, Waller DA. Palliative surgical debulking in malignant mesothelioma. Predictors of survival and symptom control (comment). Eur J Cardiothorac Surg. 2001;20:1117-21.

21. Begossi G, Gonzalez-Moreno S, Ortega-Perez G, Fon LJ, Sugarbaker $\mathrm{PH}$. Cytoreduction and intraperitoneal chemotherapy for the management of peritoneal carcinomatosis, sarcomatosis and mesothelioma. Eur J Surg Oncol. 2002;28:80-7.

22. Sabel MS, Hill H, Jong YS, Mathiowitz E, Bankert RB, Egilmez NK Neoadjuvant therapy with interleukin-12-loaded polylactic acid microspheres reduces local recurrence and distant metastases. Surgery. 2001;130:470-8.

23. Jarnagin WR, Delman K, Kooby D, et al. Neoadjuvant interleukin-12 immunogene therapy protects against cancer recurrence after liver resection in an animal model. Ann Surg. 2000;231:762-71.

24. Hsieh CL, Chen DS, Hwang LH. Tumor-induced immunosuppression: A barrier to immunotherapy of large tumors by cytokine-secreting tumor vaccine. Hum Gene Ther. 2000;11:681-92.

25. Paillard F. Immunosuppression mediated by tumor cells: A challenge for immunotherapeutic approaches. Hum Gene Ther. 2000;11:657-8.

26. Marzo AL, Fitzpatrick DR, Robinson BW, Scott B. Antisense oligonucleotides specific for transforming growth factor beta2 inhibit the growth of malignant mesothelioma both in vitro and in vivo. Cancer Res. 1997;57:3200-7.

27. McHugh RS, Shevach EM. The role of suppressor T cells in regulation of immune responses. J Allergy Clin Immunol. 2002;110:693-702.

28. Barton DP, Blanchard DK, Michelini-Norris B, et al. Serum soluble interleukin-2 receptor alpha levels in patients with gynecologic cancers: Early effect of surgery. Am J Reprod Immunol. 1993;30:202-6.

29. Belehradek J Jr, Barski G, Thonier M. Evolution of cell-mediated antitumor immunity in mice bearing a syngeneic chemically induced tumor. Influence of tumor growth, surgical removal and treatment with irradiated tumor cells. Int J Cancer. 1972;9:461-9.

30. Hiramoto RN, Ghanta VK. Surgical adjuvant chemotherapy of metastatic murine osteosarcoma. Int J Cancer. 1980;25:393-7.

\section{Discussion}

Dr G. Alexander Patterson (St Louis, Mo). As I understand it, the adenoviral vector injection was made into the tumor cells (ie, directly into the tumor mass)?

Dr Singhal. Right.

Dr Patterson. Why would you have to do that? Why not, for example, utilize an intramuscular injection or an intravenous injection? Why do you have to put it in the tumor?

Dr Singhal. Dr Patterson, thank you for your question. Intratumoral delivery of gene therapy is designed to minimize systemic toxicity. The idea is that transduced tumor cells will express high levels of interferon- $\beta$ in the local tumor environment only. This approach minimizes toxicity of the vectors. Furthermore, we have found that to establish the maximal antitumor immune response, we need to transduce tumor cells with Ad.IFN- $\beta$. This is probably due to the expression of high local concentrations of interferon- $\beta$ in conjunction with tumor antigens.

Dr Bryan Meyers (St Louis, Mo). Could you just elaborate on how you came upon the 3 days as the lead time between the injection and the surgery? It seems like maybe longer would be better. I can see that any shorter might not be enough time, but how did you come upon 3 days?

Dr Singhal. One goal of our experiments is to determine the optimal timing for the immunogene therapy. We are trying to determine when the $\mathrm{CD}^{+}$T-cell population is maximized by Ad.IFN- $\beta$ therapy so residual tumor cells cannot implant. We have tried giving Ad.IFN- $\beta$ at the time of surgery, 3 days before, 7 days before, and 10 days before surgery. Each time we performed a Winn assay, which is a technique we utilized to detect antitumor cells. So far our data has demonstrated that 3 days before surgery is the best time to treat the mice. Whether this will translate to humans is not clear.

Dr Frank W. Sellke (Boston, Mass). How long does this memory last where you give the interferon and you get the increased level of CD8 cells so that it does prevent tumor recurrence?

Dr Singhal. We have challenged "cured" mice with viable tumor cells up to 30 days following their resection. The mice that were cured with Ad.IFN- $\beta$ followed by surgical resection completely resisted rechallenge. In contrast, the rare mice cured with surgical resection alone were not protected from rechallenge. No time points greater than 30 days were assessed.

Dr Sellke. How long does the effect last? You resected the tumor, yet you have a beneficial effect on reinjecting more tumor cells, is that correct?

Dr Singhal. When we rechallenge the mice with tumor cells, we inject the tumor cells either the day of or the next day. I don't think the Ad.IFN- $\beta$-transduced tumor cells actually last very long. I think that due to the innate immune system, the T cells come back and attack transduced cells, which are now recognized as foreign. However, we have followed them as far as 60 days and have had no recurrence.

Now, we have taken a subset of mice in 1 of the 5 experiments. We challenged them at 30 days. In that case, we still had a twofold smaller tumor burden in mice that did recur. It is important to note that all the mice do recur. They just grow back at a slower rate. It is not that if there are 20 mice in the experiment, 3 mice grow back and 17 do not grow back. They all eventually do recur, but they recur at a much slower rate. This allows us to consider other interventions.

Dr Sellke. Can you readminister the gene therapy or is there some downside to giving it several times? Could you give the gene therapy, say, every month or 2 to slow the recurrence further?

Dr Singhal. We have not done it, but I suspect it would not work for 1 reason. I think we would develop an immune response to the virus. I suspect it is a 1- or 2-shot deal. After the second treatment, you probably get a strong immune response to the actual adenoviral vector and probably would not get good transduction of tumor cells. 